\title{
LA-UR-13-21541
}

Approved for public release; distribution is unlimited.

Title:

Author(s):

Intended for:

\section{Ultrafast Laser Fabrication: a Rapid Prototyping Capability for CINT}

\author{
McCulloch, Quinn \\ Dattelbaum, Andrew M. \\ Nath, Pulak
}

These powerpoint slides are for informational purposes for Frank Gac to demonstrate our CINT facility femtosecond laser prototyping capability.

Disclaimer:

Los Alamos National Laboratory, an affirmative action/equal opportunity employer,is operated by the Los Alamos National

Security, LLC for the National NuclearSecurity Administration of the U.S. Department of Energy under contract DE-AC52-06NA25396. By approving this article, the publisher recognizes that the U.S. Government retains nonexclusive, royalty-free license to publish or reproduce the published form of this contribution, or to allow others to do so, for U.S. Government purposes.

Los Alamos National Laboratory requests that the publisher identify this article as work performed under the auspices of the

U.S. Departmentof Energy. Los Alamos National Laboratory strongly supports academic freedom and a researcher's right to publish; as an institution, however, the Laboratory does not endorse the viewpoint of a publication or guarantee its technical correctness. 


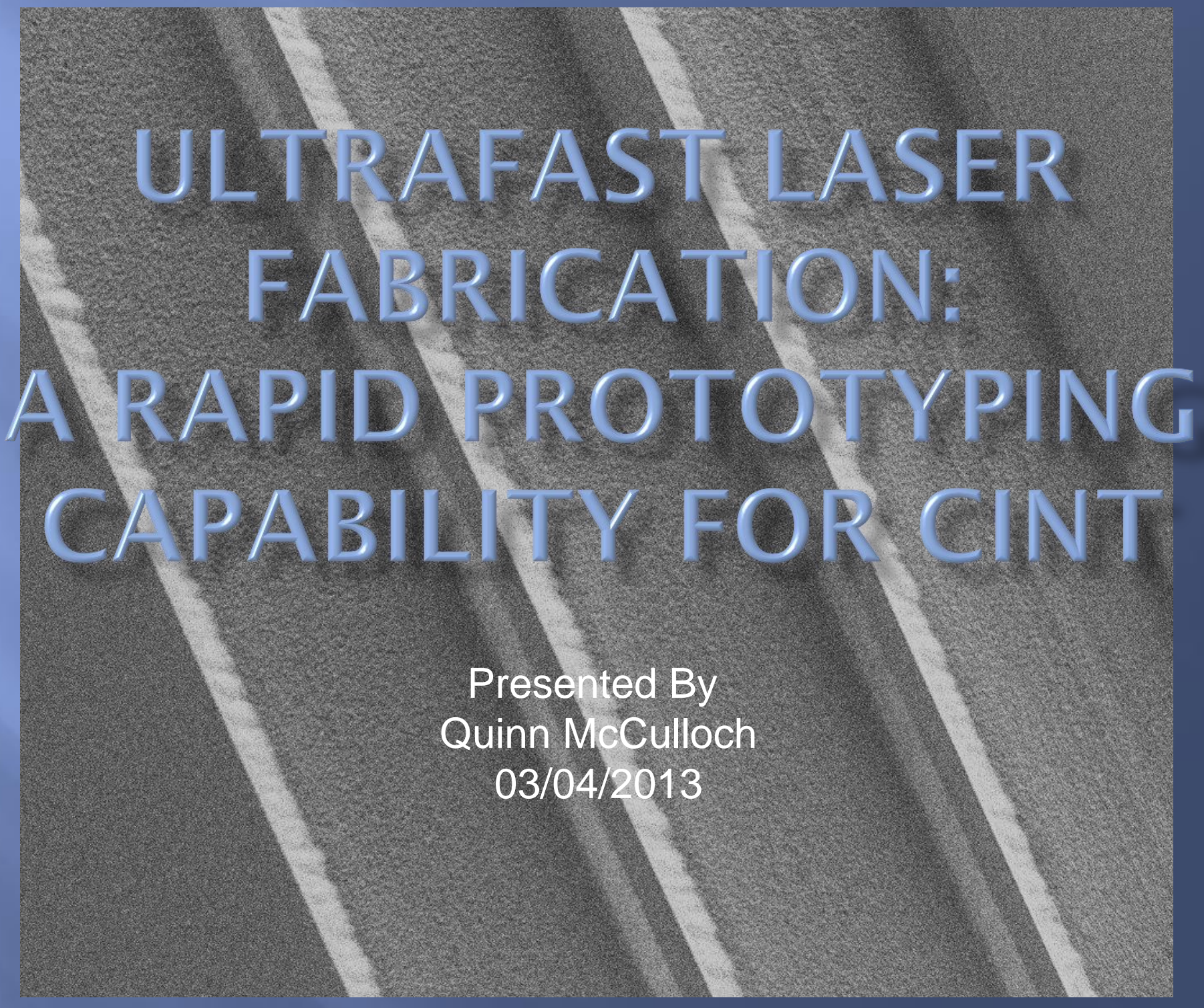




\section{Why Ultrafast?}

口 High peak intensity ( $>50 \mathrm{MW}$, unfocussed) due to 800 femtosecond pulse width

口 Non-wavelength dependant machining

- Vs. Excimer or CO2 lasers

口 Deterministic Damage Threshold

- $<1 \%$ as apposed to $20-50 \%$

口 Athermal Processing

Multi photon processing

口 OCI/ Optical Thresholding

- $\mathrm{D}=\sigma(8 \ln (\mathrm{E} / \gamma))^{\wedge}(1 / 2)$

- $<35 \mathrm{~nm}$ features demonstrated

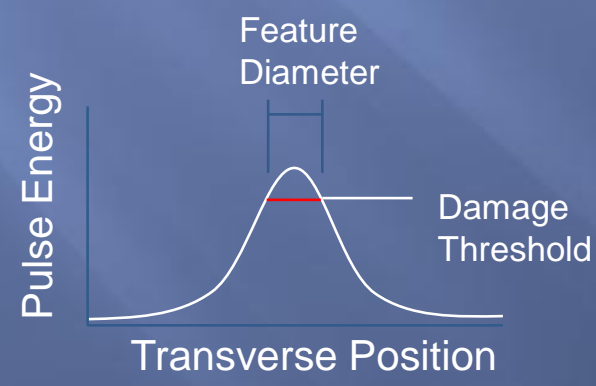

Metal ablation with femtosecond (upper) vs. nanosecond (lower) ablation. Image courtesy of Raydiance, Inc.

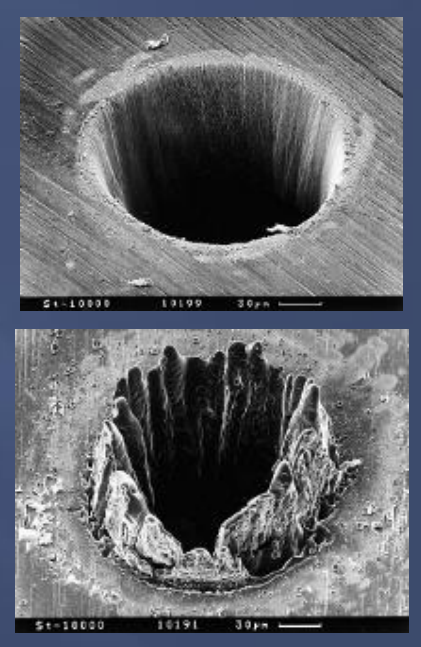

Transverse Position 


\section{Mlicrofluidics}

Collaborators: Pulak Nath, Kyle Staggs, Raydiance, Inc., Michaelann Tartis, Andrew Dattelbaum.

-Microfluidic devices with $100 \mu \mathrm{m} \times 100 \mu \mathrm{m}$ channels and 25-50um pinch points for droplet and/or micro bubble generation.

-Devices fabricated in 20 min using femtosecond prototyping system.

Rapid prototyping of robust and versatile microfluidic components using adhesive transfer tapest

, * Derek Fung, Yuliya A. Kunde, Ahmet Zeytun, Brittany Branch and Greg Goddard Received 4th February 2010, Accepted 12th May 2010 DOI: $10.1039 / \mathrm{c} 002457 \mathrm{k}$
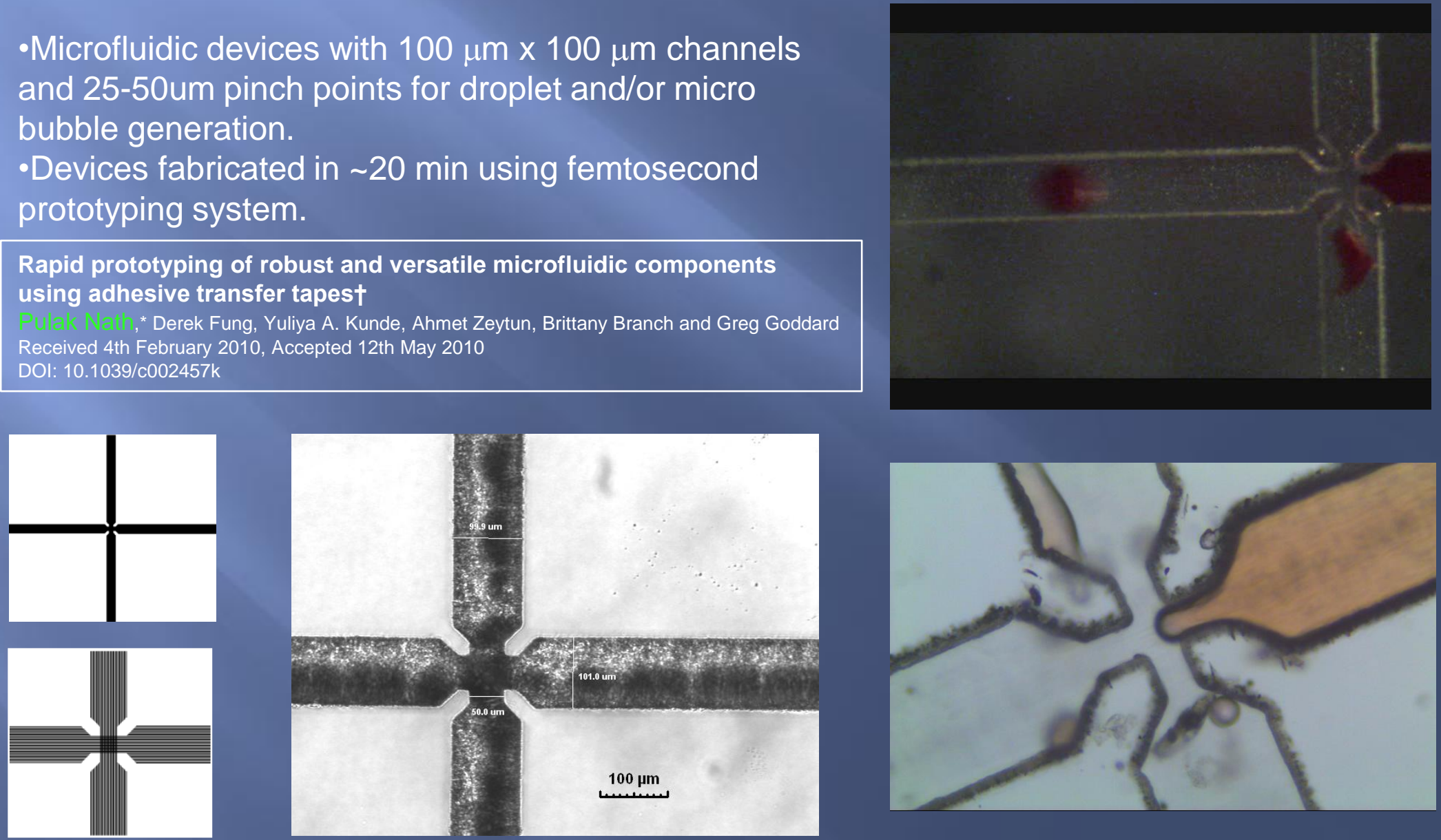


\section{Unusual Applications}
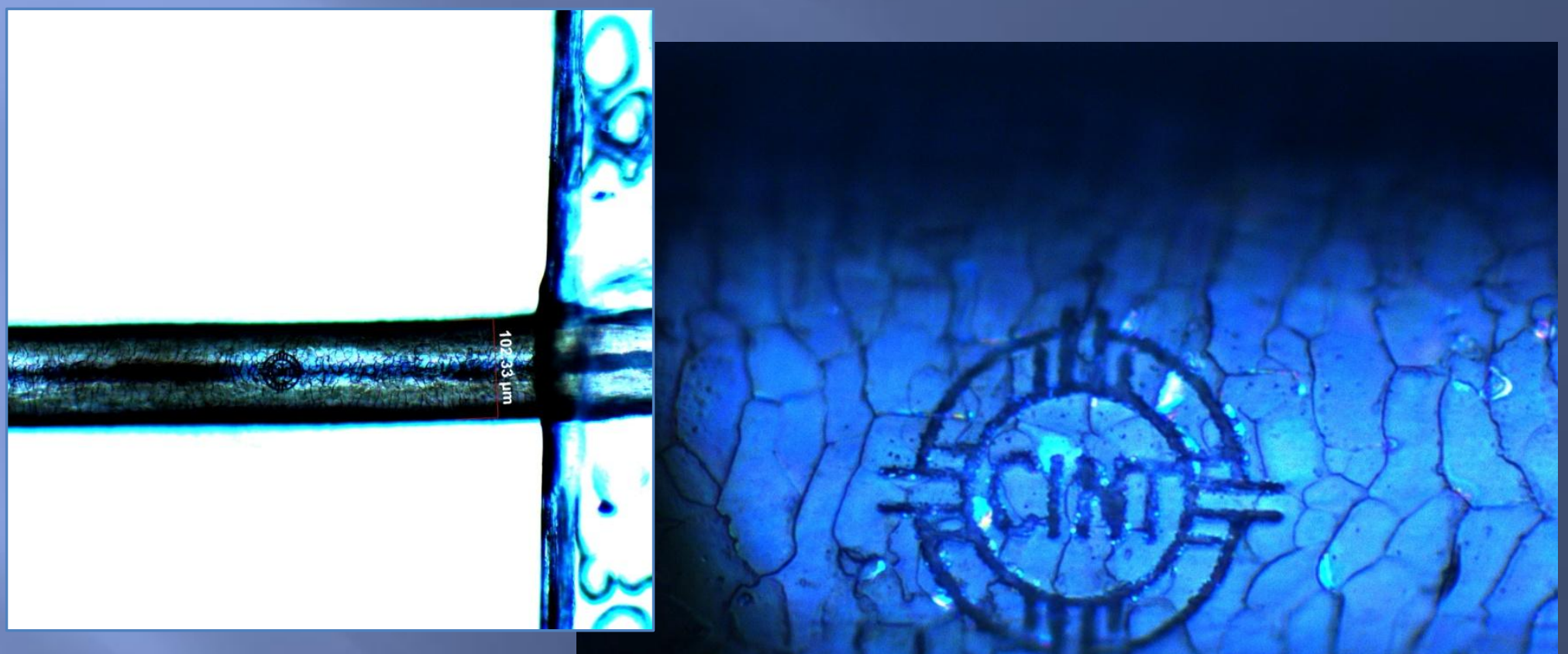

Femtosecond laser machining on

a human hair. Image width is $\sim 40$ microns.

Processing $\lambda=1552 \mathrm{~nm}$, $100 \mathrm{kHz}$ laser repitition rate. Processing time $<30$ s. 